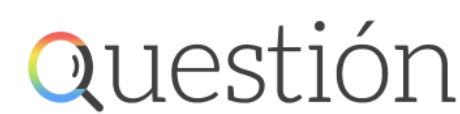

Periodismo / Comunicación ISSN 1669-6581
- Av. $44 \mathrm{~N}^{\circ} 676,1^{\circ}$ piso

CP 1900 - La Plata - Argentina

(www.perio.unlp.edu.ar/question

Vivr en bucle. Niñeces, Aislamiento y Afectividad

Karina Vitaller - Candela Luquet - Brenda Marques dos Santos

https://doi.org/10.24215/16696581e353

\title{
Vivir en bucle. Niñecesi, Aislamiento y Afectividad
}

\section{Live in a loop. Childhood, Isolation and Affectivity}

\begin{abstract}
Karina Vitaller
Profesora y Licenciada en Comunicación Social. Investigadora y extensionista. Trabajadora con perspectiva lesbofeminista e inclusiva. Docente del seminario Enseñar y aprender desde un paradigma inclusivo para el profesorado en comunicación social (FPyCS). Equipo del área niñez actores y territorios del Observatorio de Jóvenes ez -Comunicación y Medios pertenecientes al Instituto Aníbal Ford, FPyCS. Docente para la Cátedra Prácticas Culturales en la UNAJ. Directora del espacio de violencia de genero de la FPyCS perteneciente a la Secretaria de Género vitallerkarina@gmail.com

Candela Luquet

Profesora y Licenciada en Comunicación Social. Docente del seminario Enseñar y aprender desde un paradigma inclusivo para el profesorado en comunicación social FPyCS. Equipo del área niñez actores y territorios del Observatorio de Jóvenes Comunicación y Medios pertenecientes al Instituto Aníbal Ford, FPyCS. Programa UNLP de Fortalecimiento de Acciones de Restitución de Derechos de niños niñas y adolescentes. cande.luquet@gmail.com

Brenda Marques dos Santos

Profesora y Licenciada en Comunicación Social. Docente del seminario Enseñar y aprender desde un paradigma inclusivo para el profesorado en comunicación social FPyCS Equipo del área niñez actores y territorios del Observatorio de Jóvenes Comunicación y Medios pertenecientes al Instituto Aníbal Ford, FPyCS. Programa UNLP de Fortalecimiento de Acciones de Restitución de Derechos de niños niñas y adolescentes. breen.16.94@gmail.com
\end{abstract}

\section{Palabras clave}

Niñez - Aislamiento - Afectividad

\section{Keywords}

Childhood - Isolation - Affectivity

\section{Escenario 1. Escritura en cuarentena}

Vivo frente a Plaza Moreno. Escribo, borro, fumo, miro la ventana que da a una pared vacía, manchada, donde cuelgan cables y se dibujan ventanas cerradas. Se oyen desde mi piso, algunos ruidos de autos, alguna sirena, una alarma de cochera y otra de un auto que siempre suena incansable a la misma hora. 
No hay música, no llegan a mi ventana grititos de niñes correteando por la plaza, no hay estudiantes bullicioses en el horario de salida de la escuela. No hay bombos, ni marchas, ni bocinazos por las calles cortadas. Ni siquiera suenan las campanas de la catedral. Ni siquiera mi casa suena, el silencio nos habitó y hasta a las palabras les cuestan salir. Se escuchan notificaciones de los celulares y computadoras, de a ratos suena algún youtuber español seguido por mi hijo adolescente o alguna clase virtual de mi hijo universitario. El teclado es el único sonido que se escucha a más de sesenta días de aislamiento social, preventivo y obligatorio. Ni siquiera el gato maúlla en esta casa. Ni ladran los tres perros de mi vecina de abajo, ni suenan los acordes de la guitarra del vecino que practicaba incansablemente hasta la madrugada de mis noches de insomnio.

Ya se terminó el furor de la cocina, de las series, de los momentos compartidos, ya se asumieron rutinas que nos conectan con otras rutinas como la mesa familiar, el desayuno, las tareas domésticas.

Suena una notificación de mi pc con aportes de mis compañeras de escritura, recordándome qué nos motivó a aceptar esta invitación a escribir. Necesitamos decir, necesitamos compartir lo que estamos viendo, estudiando, reflexionando, pero también necesitamos expresar que no somos ajenas a este escenario, escribimos con toda la territorialidad encima, con las mismas angustias, las mismas necesidades, los mismos temores y la misma ansiedad de futuro que de quiénes vamos a esbozar unas palabras precarias, contingentes, pero que traen consigo una historia de silencios que exceden este tiempo y espacio tan peculiar, y quiénes seguramente, serán les que salgan al mundo del futuro con el mayor peso y con las más profundas marcas de haber vivido esta experiencia.

Vamos a escribir sobre les niñes del aislamiento, la generación del Covid 19, ya están refiriendo por ahí. Para ello, entrevistamos a más de 30 niñes, mediados por algunas maestras, por algunas madres/amigas que, comprometidas con su tarea de conocer a sus hijes y estudiantes, y entender los procesos que están transitando, nos ayudaron a circular una propuesta que recopilara historias "de un día" de sus vidas en cuarentena. Dialogaremos con voces del conurbano bonaerense y de los alrededores de la ciudad de la Plata. Esperamos como adultes, poder hacer justicia cuando retomemos sus palabras y no caer en un discurso adultocéntrico al interpretarles. 


\section{Escenario 2. El territorio}

Nos gusta pensar el territorio, como alguna vez lo describió Rosana Reguilloii (2006) para una entrevista donde reflexionaba acerca del posliberalismo en América latina, el consumo y el vaciamiento de lo público, la antropóloga e investigadora mexicana señalaba que un territorio, es una identidad, es un consumo, es una forma de ser ciudadano que uno lleva a cuestas. Parafraseando la película colombiana, podemos decir que estamos en este momento frente a "la estrategia del caracol", donde uno lleva a cuestas el territorio. En tercera dimensión, es como si de pronto estos procesos brotaran de las alcantarillas espontáneamente imprimiendo-lo que me parece más interesante, grave y al mismo tiempo, desafiante- sus propias rutinas y sus lógicas. Ya uno no hace hablar al territorio, sino el territorio te hace hablar a ti. Pensar en la territorialidad en tiempos de pandemia, nos obliga a pensar en qué tipo de territorialidad se está configurando y qué tipos de identidades se están reescribiendo a partir de este "presente continuo" que nos posiciona en lugares que a simple vista, parecerían iguales, hermanades en una lucha contra el enemigo común (Covid 19) y a su vez desde posiciones con valores desiguales. Si bien el riesgo es generalizado, parecería que en esta batalla contra el virus hay quienes la pelean con recursos simbólicos y materiales y otres cuerpo a cuerpo. Algunes ponen en juego la salud y otres sus vidas.

Este enemigo que se despliega entre fronteras materiales y simbólicas acecha contra conquistas que algunes creímos consagradas, y la precariedad de nuestras existencias, de nuestras posesiones, de nuestras autonomías, de nuestras luchas, de nuestra idea de libertad, de nuestra proyección sobre el futuro y hasta de nuestra percepción sobre el tiempo, se diluye y se reconstruye de acuerdo a estadísticas mediáticas y a conferencias de prensa de las autoridades. El Covid-19 desbarató rutinas, prácticas, tradiciones, y vino a visibilizar un ordenamiento de nuestras existencias que en algún momento naturalizamos y lo creímos tan propio que hoy nos deja en la incertidumbre y en la dependencia de quienes tienen el deber de resguardar la paz social, la seguridad y el cuidado de todes.

Nunca supimos con certidumbre qué sería del futuro, pero amanecíamos con proyectos a corto y a largo plazo, dueñes de nuestro tiempo, de nuestro porvenir. Ahora necesitamos respuestas, coordenadas, directivas que nos orienten como seguir, como organizarnos como reordenarnos. 
La única certeza que tenemos y que esta pandemia visibilizó con obscenidad, es que la vulneración de los derechos vitales como el alimento, el agua, el techo, el trabajo se vuelven signos que ya no clasifican entre incluides y excluides, sino entre supervivencia o muerte.

Esta marca, devenida de la profundización de la pobreza provocada durante los últimos años del abandono y la violencia perpetrada por las políticas liberales que eligieron el capital financiero por sobre el capital humane, la salud y bienestar de les ciudadanes, son decisiones que hoy se vuelven condenatorias para quienes esta política excluyó. Así, países como Brasil y Estados Unidos priorizan la economía desde la lógica del "sálvese quien pueda" y hoy ocupan el ranking de los países con más muertes e infectades de Covid 19 definiendo de esta forma, como plantea Judith Butleriii (2020), si las diferencias de clase, raza o de género se inmiscuyen en el criterio con que juzgamos qué vidas tienen derecho a ser vividas también sabremos cuáles no.

En éstos días, se instala en nuestro país el lema de la economía se vuelve, de las muertes no, de esta forma se decide decretar un aislamiento social preventivo y obligatorio que a la fecha del presente artículo lleva más de sesenta días, y como práctica que va a intentar reparar el daño sufrido por la población más castigada durante los últimos años, se sancionan políticas públicas como el IFE (Ingreso Familiar de Emergencia), aumentos en la AUH (Asignación universal por hijo), de las jubilaciones y en el monto de la tarjeta Alimentar, entre otras medidas, que intentan contribuir al mejoramiento de la calidad de vida de quienes han sido vulnerades en sus derechos esenciales, como estrategia de preservar la mayor cantidad de vidas.

Así, preguntarnos sobre la territorialidad nos obliga a pensar en las identidades que se van reescribiendo a partir de esta catástrofeiv. El territorio para la gran mayoría, sigue siendo el aislamiento habitacional, aún para aquelles que han sido convocades para tareas esenciales y para nuevas actividades que han empezado a habilitarse. Sin embargo, la forma de ser habitado y habitar estos territorios van a estar signados por las condiciones materiales de nuestras disposiciones en el espacio social, y éstas no va ser igual, ni van a significar la misma territorialidad. Atravesar la cuarentena en un departamento en el centro platense o en cualquier casco urbano, con servicios básicos garantizados qué atravesarlas en un barrio popular o un asentamiento, en condiciones de hacinamiento, en los que, la mayoría de las veces, no hay energía eléctrica, ni redes de agua potable, ni espacios garantizados para pasar las 24 horas del día en aislamiento. 


\section{Escenario 3. Las niñeces en tiempos de Covid 19}

El reconocimiento del niño como sujeto de derecho significa necesariamente otorgarle la debida participación integrándolo en los procesos que conciernen a su vida y su persona.

Durante las últimas décadas del siglo pasado, se instala a partir de la Convención Internacional de los Derechos del Niño, la noción de sujeto de derecho, la cual en nuestro país se cristaliza en la ley de Protección integral de los derechos de los niños, niñas y adolescentes (ley 26061 Sancionada en el año 2005). La noción de sujeto de derecho viene a visibilizar o por lo menos asume el desafío de intervenir esta mirada discapacitante "el niñe que no puede", inhabilitante, de tutela, de silencio y sin agencia acerca de las niñeces, y a reconocer desde el campo de lo normativo, una serie de supuestos basados en el interés superior del niñe. Desde ese paradigma, instituye, el derecho a ser oído, a la expresión del niñe, niño, niña, la promoción y Protección de sus derechos humanos y fundamentales en corresponsabilidad con todes les efectores de la ley en el marco de un sistema de promoción y protección. Asumen por lo menos normativamente las niñeces así, una instancia de participación valedera, ya no como sujeto de tutela, sino como sujeto protagonista.

En este marco, se sancionaron varias legislaciones que en coherencia con un paradigma inclusivo, vinieron a restituir derechos que habían sido denegados, de las cuales las niñeces fueron beneficiadas de forma directa. Enseñanza multicultural y bilingüe, los programas de inserción al mundo digital de la mano del Conectar Igualdad, la ley de identidad de género que permitió que la niñez trans pueda constituirse en una identidad legítima, (por lo menos jurídicamente), la ley de servicios audiovisuales que apeló a la producción de una serie de materiales de divertimento altamente formativos en valores que disputaron sentidos colonialistas y patriarcales, una gran apuesta en presupuesto para la educación, donde pasaron a ser obligatorias ambos niveles formativos (primaria y secundaria), además de la creación de nuevos centros educativos, la asignación universal AUH, programa de asistencia de inclusión y retención escolar, la inserción de las personas con discapacidad al sistema educativo formal, la ley de Educación sexual Integral ESI, el voto joven (16 años) entre otras tantas medidas, que promovieron cambios muy significativos para esa generación de niñes.

Tras el vaciamiento y saqueo de los últimos años, estas políticas sino fueron finalizadas, fueron precarizadas, o desfinanciadas. Todas las conquistas alcanzadas, se vieron gravemente 
amenazadas cuando no desarticuladas, arrojando a la pobreza y a la desprotección a miles de niñes dependientes de familias $\sin$ techo, sin trabajo, sin políticas públicas que los contengan. Está claro que hay otras niñeces con algunas otras garantías y capitales, lo que no las pone en un lugar de privilegio, sino en una posición de derechos menos vulnerados, sin embargo ser niñe en cualquier disposición del campo social, comprende un lugar de varias subalternidades.

Estas subalternidades se basan en desigualdades materiales y simbólicas; de dependencia jurídica, económica, afectiva, por desigualdad de poder, de fuerza, de legitimidad respecto a sus opiniones y decisiones, de capital cultural, entre otras. Subalternidades legitimadas algunas normativamente y otras por la herencia simbólica de un paradigma conservador y violento que resiste y se normaliza a través de un sentido común cristalizado por diferentes discursos que lo sostienen y consolidan, entre ellos, la industria cultural y el lenguaje.

En ese mapa se inscriben las trayectorias vitales de éstes niñes que entrevistamos, con mayores o menores recursos materiales o simbólicos, todes elles portan la marca del abandono del estado de alguna forma u otra. Ya sea por la realidad familiar, de desempleo, de precarización, de falta de acceso a bienes esenciales para la vida, o por la desprotección generada por las políticas liberales, que impulsaron a las familias de mejores accesos a procesos de individuación y frenético consumo, relegando las prácticas de crianza por la productividad que los tiempos requieren, relegando las prácticas de crianza por la productividad que los tiempos requieren, así también, se presentan otras realidades en las formas de experimentar las niñeces, entornos de cuidado, de protección de derechos, de promoción de valores emancipatorios, de compromiso y responsabilidad.

Hoy el aislamiento social, preventivo y obligatorio, vino a irrumpir en estas experiencias, y a visibilizarlas, todes en casa, compartiéndonos, cohabitándonos. Interpelades por el escenario pandémico que nos obliga a encontrarnos, a conocernos y reconocernos, interrumpiendo nuestras prácticas, reconfigurando nuestras rutinas, restringiendo la circulación en la vía pública y el contacto con les otres. Confinándonos a la esfera de lo doméstico, ese universo que suele ser bien conocido por les niñes y por (generalmente, debido a la patriarcal distribución de tareas) las madres, abuelas $\mathrm{u}$ otras identidades feminizadas y que ahora, salvo que les padres realicen alguna actividad esencial, también habitada por ellos.

En este escenario que se presenta de forma romantizada como "la familia unida", la vuelta al modelo conservador de familia, acecha desde las publicidades, los discursos escolares que 
apelan a hacer las tareas con les papis y les mamis, no solo desconociendo los roles de género, sino también las distinciones, las diversidades, las ausencias, los modelos de familias diversos, la falta de capitales culturales, materiales; pero sobre todo y lo más preocupante, invisibilizando las tensiones que en el seno del "quédate en casa" se producen. Violencias, miedos, angustias, ansiedades, traumas, incertidumbres.

Atrapades en una convivencia obligatoria que puede volverse crítica cuando el dinero no alcanza, cuando la comida o el trabajo están en riesgo, cuando los espacios para la intimidad no existen, cuando los servicios escasean, cuando las tecnologías no están o son obsoletas o se usan con fines de trabajo, una convivencia sin más aire que el del patio o el del fondo (les mas afortunades), una convivencia que reproduce las desigualdades de género y violencias por razones de género entre las cuatro paredes de la casa. Según UNICEF "Los niños y los jóvenes, además de estar contrayendo la Covid-19, son algunas de las víctimas a las que más duramente afectará el virus. Si no actuamos de inmediato para abordar las consecuencias que la pandemia tendrá sobre los niños, el eco de la Covid-19 causará daños permanentes en nuestro futuro común".

Si bien esta coyuntura nos atraviesa afectándonos a todes, les más perjudicades son les niñes, quienes se quedaron sin la posibilidad de salir a encontrarse con amigues, de visitar a su familia extendida, de participar de otros espacios, de quedarse sin compañeres de escuela, sin sus maestras, profesores, vecines. Quedaron sin espacios de interacción con otres, sin la oportunidad de establecer diálogos sobre sus intereses, sus preocupaciones, sus sentimientos, sus secretos, sus denuncias. Les niñes en la casa son hijes, y es el único rol se les permite jugar, además del rol asignado a su (supuesto) género, aspecto que vamos a apreciar cuando compartamos sus voces.

Lo más preocupante de la situación que les niñes atraviesan, es que se está produciendo en el marco de una sociedad fuertemente adultocéntrica y conservadora, en la que las rutinas de les niñes están sujetas a las de les adultes, en la que pareciera no haber lugar para sus opiniones, ni tampoco interés acerca de sus preocupaciones, miedos, y sentires acerca de la catástrofe que están atravesando debido al aislamiento, como así también los miedos o inseguridades que devienen del estar confinados en sus hogares. Maltratos, abusos sexuales y de poder, explotación, o prácticas de abandono (aun compartiendo el techo), violencias por cuestiones de género, reproducción de roles sexistas, discriminaciones, subestimaciones, bullyng, y otras 
tantas formas de violencias a las que les niñes están expuestes, sin poder recurrir a las redes que están a disposición de les adultes para las mismas circunstancias. Consideremos que no todes les niñes tienen acceso a un dispositivo de conexión personal, ni siquiera a espacios de privacidad.

"Según nuestros análisis", señala UNICEF, "el 99\% de los niños y los jóvenes menores de 18 años de todo el mundo (2.340 millones) vive en alguno de los 186 países en los que se han impuesto distintas formas de restricción a los desplazamientos debido a la COVID-19. Además, el $60 \%$ de todos los niños vive en alguno de los 82 países que se encuentran en aislamiento total (7\%) o parcial (53\%), lo que equivale a 1.400 millones de jóvenes.

Confinados a vivir todos los días como si fuesen el mismo, desayunar, ayudar en la casa, jugar un ratito, poner la mesa, levantarla, ver la tele, hacer deberes soles, con hermanes, con mamá, con papá (según sus relatos) jugar o ver la tele, merendar, seguir con las tareas, jugar con alguna mascota, o soles o con hermanes, poner la mesa, levantarla, ver la tele soles o con familia y dormir, para luego comenzar con la misma rutina. Imaginémonos en esa monotonía, como un bucle las rutinas solo distinguen el día y la noche. Supervisades en el juego, en la comunicación, en la higiene, en las tareas, en el uso de las tecnologías, no hay lugar donde fugarse, ni material ni simbólico. Jugando siempre el mismo papel, cumpliendo siempre las mismas órdenes.

La escuela que se constituía como el escenario de encuentro con les otres, donde dejar de ser hijes por un rato, donde ser un poco más elles mismes, dónde se puede circular por otros espacios, con otros rituales con otros sentidos, donde aprender cosas nuevas (no solo de les maestres), donde socializar, donde construir prácticas colectivas, donde se apela al uso de la palabra, de la escritura, de la expresión, donde se juega, donde se enamoran, donde se puede trasgredir con menos riesgos, donde se puede contar aun sin palabras los padecimientos domésticos, porque hay personas idóneas para leer lo no escrito en palabras y sí en conductas. Ese lugar, donde a veces también se les asegura una mediación familiar, un plato de comida, un paseo, una ventana a un mundo que algunes solo conocerán en los libros o en los mapas colgados de la pared, pero que abre y no clausura, ese lugar que es la escuela, hoy tiene las puertas cerradas y aunque haya otros dispositivos en acción para sostener los procesos de enseñanza aprendizaje, al estar mediados por les adultes, se vuelve muy difícil canalizar por ahí cualquier tipo de situación que ponga riesgo el bienestar de les niñes. Señala UNICEF "Por anteriores crisis de la salud, sabemos que los niños están más expuestos al peligro de ser 
víctimas de explotación, violencia y abuso cuando cierran las escuelas, se interrumpen los servicios sociales y se restringen los desplazamientos. Por ejemplo, el cierre de las escuelas durante el brote del ébola en África Occidental de 2014 a 2016 contribuyó al repunte del trabajo infantil, el abandono, el abuso sexual y los embarazos de adolescentes. Además, la forma de violencia más común a la que se enfrentan los niños tiene lugar en el hogar. En una mayoría de países, más de dos de cada tres niños son víctimas de castigos violentos por parte de sus cuidadores ¿Qué pasa entonces cuando no hay a donde ni a quienes recurrir?

\section{Escenario 4. Voces}

Aislades de amigues, compañeres, vecines, docentes, otres familiares, separades de espacios en los que podían expresarse, ser contenides, ser escuchades. Estes niñes hoy se encuentran conviviendo con adultes. Personas que continúan sus rutinas diarias, la gran mayoría dentro de sus casas, pero saliendo por compras, o por tareas esenciales, permitiéndose alguna charla en la vereda con pares, o hablando por teléfono con amigues, o chateando, disponiendo de su tiempo a su antojo, reacomodando sus rutinas sin pedir permiso, expresando de qué manera atraviesa la pandemia y el aislamiento obligatorio, sus miedos, preocupaciones, ansiedades, sus sentires, describiendo sin preguntar como la están pasando les niñes de la casa, con vecines, amigues, en las redes, en la vereda, en los comercios, en los medios de comunicación.

Así, este equipo de docentes, de investigadoras, de trabajadoras que desde hace más de cinco años nos dedicamos a analizar, estudiar y describir diferentes cuestiones respecto a las niñeces y la vulneración de derechos, hemos incursionado desde nuestra formación en comunicación en distintas problemáticas que atraviesan las existencias de les actores sociales niñes. Hemos estudiado aspectos vinculados a los consumos culturales, al género, a la educación, a las violencias, y en este contexto, no podíamos dejar de preguntarnos ¿qué estarán queriendo expresar les niñes en este aislamiento?, ¿quiénes les escuchan?, ¿con quiénes interactúan?, ¿en qué condiciones?, ¿qué derechos les estarán siendo vulnerados?, ¿con qué recursos subjetivos contarán para enfrentar esta catástrofe?, ¿qué traumasv devendrán de ésta?

De esta manera, armamos nuestro protocolo de entrevista, corto, pero que nos permitiera poder recabar la mayor cantidad de información. Lo redujimos a dos preguntas: ¿Nos podes contar como es un día de tu vida en cuarentena? y cuando te vas a dormir, ¿qué es lo que más extrañas? 
Si bien para nuestra legislación les niñes son personas que van desde el momento de su nacimiento hasta los 18 años de edad, decidimos recortar entre personas de entre 10 y 12 años, reconociendo que les niñes de 10 años aún asisten a la escuela primaria y son considerados "niñes" y les de 12 años, considerados "pre- adolescentes" según algunas categorías, cursando en el nivel de secundario de educación obligatoria. Esta diferenciación buscaba identificar intereses distintos en los relatos, pero finalmente, no hay distinción entre unes y otres. Las entrevistas fueron realizadas por amigas, y docentes que empatizaron con la propuesta. De las 30 entrevistas recibidas, la mayoría fueron audios de WhatsApp de les propies niñes, otras por escrito.

Una observación que no podemos ignorar es que estes niñes se narran desde espacios que los habitan, llevan su territorio a cuestas; cuando hablan con su maestra, así como cuando les entrevistan sus madres, sin intenciones de sobre interpretar, pero sí de ver lo "no dicho" haremos inferencias en cada relato. A propósito una maestra que también es psicopedagoga e integra el equipo de orientación escolar, cuando nos pasó sus entrevistas señaló: "La sensación que me da escucharlos ahora, es la misma que me dan sus cuerpos tapados con el guardapolvo cuando están en la escuela".

\section{Sentires:}

- Hola Seño yo acá en esta cuarentena me siento normal, nnno, no cambio nada acá solo. Lo único que cambió es que no puedo salir, tampoco no puedo ir a la plaza, no puedo jugar futbol y no puedo ir de viaje, eso es normal", Bautista entrevistado por su mamá señala: "La verdad, no extraño nada"

- $\quad$ "El día de mi cuarentena es divertido. Juego con mi primo al metegol, juego con mi perro porque tengo un patio grande, y y y eso. Está muy linda la cuarentena"

- "En la cuarentena la estoy pasando más o menos, me la paso jugando con un perro, con el cual me divierto mucho!"

- "Quiero que pronto pase todo esto que podamos volver a la normalidad no aguanto más se hace eterna está cuarentena".

- " "me voy a bañar y después a dormir y otra vez lo mismo."

- " "pero yo... estoy muy bien... no, no tanto, no estoy tan bien, no salgo yyyyy chau!"

- " "bueno a veces me siento un poquito aburrida a veces" 
Es interesante ver en estas reflexiones, como hay cierta naturalización de la cuarentena, del estar en la casa, de las rutinas de estudio y juego, lo que más se advierte en estas frases y en el resto de las entrevistas es la imposibilidad de circular, de jugar con otres y en otros espacios, de compartir con otres, familia, amigues, compañeres de escuela, maestres, vecines. Evidentemente la vida pautada y planificada que les adultes les construimos a les niñes, es tan parecida al aislamiento social que elles no estarían advirtiendo la diferencia, salvo por los aspectos mencionados. Sin embargo, al escuchar los audios, es notorio, como les cuesta admitir que algo no está tan bien, se advierten los silencios, las interjecciones, los ritmos de la voz, la respiración entrecortada, sus voces se vuelven tímidas, la impostación de la voz al hablar de aspectos emocionales. ¿Cómo estarán tramitando esto les niñes?, ¿qué recursos subjetivos tendrán para hacerle frente a las heridas subjetivas que dejará este asilamiento?

Un caso muy interesante fue el de una niña que no lograba articular palabras por escrito, cuando fue invitada a participar de esta experiencia, le sugirieron que lo haga por audio, para que escribir no fuese un impedimento, y la niña, por primera vez en mucho tiempo, expresó por escrito, como era su día en cuarentena.

En las narrativas de les entrevistades se desprenden varias ideas que trataremos de describir como para poder entrar en ese mundo de días eternos que están viviendo las niñeces sin distinción de disposiciones sociales.

Las lealtades: $Y$ después si empiezo hacer la tarea con la ayuda de mi mamá mientras tanto tomamos unos mates con lo que haya para comer siempre o mejor dicho casi siempre mi mamá hace torta de manzana o algo para el mate (me gusta tomar mate) pero prefiero más el té. A ella no le gusta el mate, lo reafirma al poner la frase entre paréntesis no me gusta pero... así les niñes, muchas veces son quienes acompañan, quienes cuidan, quienes renuncian a sus gustos por el otre, Cande, quien vive con su mamá, prepara café por las noches, porque siempre algunas de las dos se queda despierta mientras la otra duerme.

Las rutinas: desayunar, a las 9 o a las $13 \mathrm{hs}$, pero parece ser el ritual de todes les niñes entrevistades, la mayoría comparte con miembres de su familia este momento. Rescatan como bueno estos tiempos compartidos, las charlas, sobre todo. Compartir con la mamá o con papá o con ambos algún momento, Facu ,12 años toca la guitarra con su papá, a veces, y baila en 
familia, también hace muchas actividades en soledad, tocar el teclado, jugar, mirar YouTube en su habitación, jugar con su mascota, hacer su curso de diseño de juegos, tiene rutinas semanales y ninguna escolar los fines de semana, pero Bautista de 11 años hace todo con su mamá: mirar películas, entrenar, atender la huerta, menos jugar al counter. Aldana limpia, al igual que varias niñas del grupo entrevistado. Los varones riegan plantas, hacen huerta como Bautista o ayudan en el trabajo de algune de sus progenitores, como el niño de San Carlos que fabrica empanadas con su mamá que ahora las vende en cuarentena. También es parte de la rutina de algunes niñes atender a sus mascotas. Poner la mesa, levantar la mesa luego de las comidas.

El tiempo: Bautista parece mirar el reloj todo el tiempo porque sabe que hace a cada hora y siempre son horas puntuales. Facundo también parece manejarse con muchos horarios y relata cronológicamente su día. Ambos se acuestan tarde y se levantan tarde, Bautista dice "estamos tratando de acomodarnos" Facundo se levanta tarde pero no lo cuestiona. La mayoría de les niñes relatan sus rutinas de forma ordenada, casi de memoria, como si siempre hubiese sido igual, no mencionan un "antes" y un "ahora". Una niña señala "hago ejercicio tratando que pase el tiempo", se repite la frase "y así todos los días" u "otra vez todo de nuevo"

Lo afectivo: Alma, una niña del barrio San Carlos, cuenta que extraña a sus amigas y jugar con ellas. La misma respuesta se repite en Antonella, Candela, Aldana, Santiago Lo que más extraño es poder invitar a mis amigos a casa y hablar con ellos cara a cara y jugar y disfrutar juntos. También hacer juntadas. Dante extraña a su abuela, Aldana jugar con otres, Alma a sus amigas, Tati a sus compañeres, a su maestra; Cande extraña a su padrastro y a su perro que murió por un virus; otra niña extraña su profesor de música; una niña del barrio Malvinas extraña a sus primos, y así, cada relato pone ausencias humanas en ese "extrañar".

El afuera: Facu y Otra niña de 12 señalan que extrañan ir al cine, o a otros lugares que les gusta, la plaza, ir a comer a otro lado, pasear, viajar, sacar al perro y andar en bici, otro niño agrega "al finalizar el día extraño ir a jugar a la pelota con mis amigos y mis hermanos", todes extrañan espacios compartidos con otres, el patio de la escuela, los recreos, la calle, andar en patines. 
Las redes y la tecnologías: Pocos relatan contactarse con sus amigues o compañeres de la escuela, recuperamos el caso de Facu, quien cuenta: "uso mi celular para leer y responder mensajes en WhatsApp e Instagram", al igual que otra niña que también usa Instagram para charlar con sus amigas y parece tener el horario para ello. Mía graba tiktoks. En la mayoría de los relatos aparece la tele como dispositivo de entretenimiento. Luego nombran el juego, pero no sabemos si es un juego de consola (salvo los casos explicitados) de computadora, del celular $u$ otro tipo.

Las tareas: Facu reconoce hacer tareas escolares y asume tareas en la casa comprometidas con su uso personal, hace postres y tiene espacios de formación extraescolares. Aparecen no solo les xadres como mediadores de la tarea escolar, sino también hermanes y primes. Un niño del barrio San Carlos expresa yo me levanto, me cambio, me levanto a regar las plantas, y después le ayudo a hacer empanadas a mi mamá que ahora mi mamá vende empanadas. Otres se ocupan del mantenimiento de las mascotas o las plantas. A una niña del barrio Malvinas, le faltan sus amigas para hacer las tareas "a veces nos ayudamos a hacer las tareas. Cuando íbamos a la escuela si íbamos a jugar en el recreo y a hacer las tareas en el aula"

El futuro: Facu dice Cuando termine la cuarentena quiero hacer todo lo que ahora no se puede porque no podemos salir o juntarnos. Una niña sobre las amigas "pero ¡bueno! ya va a pasar todo esto. Es lo que más quiero volver a estar con ellas".

Transgresiones al aislamiento: Mía dice: después juego con mi primita que viene a mi casa, cuando termino, a veces voy a la casa de mi prima a patinar un rato, la casa de mi prima queda a dos cuadras así que puedo ir tranquila y en la casa de mi prima patinamos y me quedo a merendar, nena del barrio El peligro relata: después voy acá, a la casa de al lado que es de mi abuela y después juego con mis primas. Después voy al quiosco acá al lado.

El juego: En los relatos de les niñes aparece frecuentemente la alusión al juego. Aldana, una niña del Barrio Malvinas, dice que extraña jugar con sus amigos y amigas y no poder "salir" a jugar. Lo que se repite en muchos de los relatos es que extrañan jugar. Pero no cualquier tipo de juego, ya que en sus relatos aparece la práctica de jugar con la mascota con los maquillajes. Se 
advierte la necesidad del juego en el espacio público, el juego que implica hacer y estar con otres. Otro niño expresa: armamos un arco con mi hermano y nos ponemos a jugar a la pelota, ya que no podemos salir a la plaza a jugar.

A través del juego, les niñes se desarrollan, se expresan, aprenden y construyen su propio mundo. También "elaboran psíquicamente los acontecimientos y circunstancias que los rodean, asimilan aspectos del mundo en que viven". Pero es también en el juego en donde les niñes aprenden a internalizar la cultura, a construir los vínculos con les otres. "Representa la cultura, el vínculo con pares, la aceptación de reglas, el establecimiento de acuerdos, la puesta en juego de valores, de la personalidad, se da en un espacio, en un momento, en un tiempo" (Kalejman, 2012).

¿Qué sucede con les niñes que no tienen hermanes para jugar o algún otro par en su hogar para poder jugar? ¿Los adultos se dan el tiempo para jugar con elles?

\section{Escenario 5. La escuela en tiempos de pandemia}

"Hola Seño, soy Iván, con las tareas me va muy bien, si no entiendo le pregunto a mi hermana y ella me explica", "Pero con las tareas estoy bien, me gustó mucho el cuento, y todo lo que mandas es bueno, las tareas" (niño de barrio San Carlos), "Con las tareas vengo bien, cualquier cosa me ayuda mi papá, como siempre", "Y también los juegos, las ideas que mandas, como esos videos de cómo hacer uno de esos diez juegos, más los cuentos, más las canciones. Pero lo que más me gustó de que mandaron todos los profes son las canciones, y el cuento que más me gustó fue el de Novazo ¿?"

La irrupción del Covid 19 obligó a tomar medidas preventivas a todos los Estados, la escuela no estuvo exenta de esto. Para evitar la propagación del virus y los contagios masivos, el gobierno nacional dispuso el cierre total de las instituciones educativas $y$, para continuar con el proceso educativo, propuso la continuidad pedagógica a través de la educación virtual. Docentes, estudiantes y familias, rápidamente tuvieron que amigarse con las nuevas tecnologías y adaptarse a este "nuevo" formato de la educación. Esto destapó innumerables conflictos que, si bien estaban presentes, el confinamiento los puso sobre la mesa.

En estos tiempos de Pandemia quienes practicamos el oficio de la docencia, tenemos más preguntas que respuestas: cómo lograr el acceso, la permanencia, cómo intervenir y con qué plataformas, con qué criterios, cómo evaluar, cómo acompañar, cómo garantizar los 
aprendizajes, cómo trabajar sin la presencia de les estudiantes. ¿Estábamos preparades para trabajar en la educación a distancia? ¿En manos de quién queda la educación de les niñes? ¿Cuánto se puede problematizar a distancia? ¿Hay lugar para la autonomía? ¿En quienes recaen las actividades escolares? ¿Quiénes quedan por fuera del sistema educativo? ¿Cómo es posible llevar adelante una educación crítica e inclusiva en estos contextos? ¿En qué situación se encuentran les estudiantes? ¿cómo construimos un vínculo pedagógico en la virtualidad? cómo ofrecer todo eso que la escuela significa para les niñes a través de whtasapp, zoom, jitsi, meet o la plataforma que elijamos cuando, nuestres estudiantes muchas veces no cuentan ni con acceso a redes de wifi, o cuando el único dispositivo electrónico es el celular que usa mamá o generalmente papá para su trabajo, y cuando ese único celular no tiene datos, y cuando no hay espacio para bajar las app, y cuando ningún miembre de la familia sabe cómo hacer funcionar esas plataformas y cuando ningún miembre de la familia cuenta con el capital cultural necesario para acompañar en estos procesos, cuando no está la panza llena y no hay un techo y una familia que pueda por lo menos intentar garantizar ese proceso.

¿Pero, qué significa la escuela hoy? ¿Cómo ser escuela "sin escuela"? Si buscamos en los

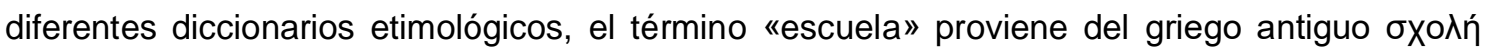
(skholế) el cual, por mediación del latín devino en schola. El significado original en griego era "tranquilidad", lo que se hace en el tiempo libre, de ocio, más tarde derivó en un sentido más productivo, seguramente por las marcas sociopolíticas de la época, pasó entonces a resignificarse como "lo que vale la pena hacer durante el tiempo libre", en oposición a los juegos, para más tarde en el periodo helenístico, utilizarla para designar a las diferentes escuelas filosóficas, donde tomó su sentido actual de centro de estudios.

Ya sabemos entonces en qué momento la escuela se centró en los procesos de enseñanza y aprendizaje, dejando de lado su sentido de esparcimiento y de tranquilidad. En la escuela hay que aprender, hay que enseñar y hoy eso está en juego. Así las cosas, les docentes, quienes van aprendiendo a la par de les estudiantes a utilizar las plataformas virtuales, con el doble de trabajo que en la presencialidad, producen y envían archivos y archivos a los classroom de les estudiantes, ocupando ese tiempo libre y de ocio que propiciaba la cuarentena para tenerles ocupades en sus días de aislamiento, así como también se intenta garantizar a través de una serie de cuadernillos promovidos por el Ministerio de Educación la misma administración del 
tiempo de ocio de aquelles que no tienen conectividad, de esta forma podrán autogestionarse el proceso pedagógico de forma autónoma.

Entonces, la escuela es ¿Pura reproducción de contenidos?, y ¿de qué sirve esa función cuando los contenidos están en la web al alcance de quienes tienen conectividad para buscarlos? en manos de quién quedan las orientaciones y seguimientos de les estudiantes? ¿Quiénes se constituyen en docentes sin saber el oficio y sin vocación? (parafraseando a Serrat)

La enseñanza virtual también nos enfrenta al desafío de sostener la perspectiva de educación sexual integral (ESI), asumiendo que ya era un desafío en la presencialidad, en la educación a distancia se vuelve mucho más difícil. El aislamiento social y la falta de dispositivos tecnológicos de uso personal en les estudiantes, hace que la información y materiales que circulan en ellos, muchas veces sean monitoreados por las familias. Teniendo en cuenta que la ESI ha posibilitado que muches niñes y adolescentes puedan romper el silencio y contarle, a algune docente, distintas situaciones de violencia y abusos que estaban atravesando ¿qué pasa cuando no hay un espacio de privacidad para pedir ayuda? ¿Qué sucede cuando les niñes están encerrados con sus abusadores? Otra de las problemáticas que surgen de la educación a distancia es la de las familias que se oponían a la Ley de Educación Sexual integral, y que ahora, con mayor control sobre las actividades escolares que realizan les niñes que tienen a cargo, les adultes censuran deliberadamente y se arrogan el derecho de decidir qué cosas van a aprender les niñes y qué cosas no. Familias y también autoridades escolares, cuestionan el uso de lenguaje inclusivo, se oponen a los contenidos que enseñan les docentes y se niegan a que sus hijes aborden ciertos contenidos que les permitan problematizar sus identidades, sus realidades, sus vínculos, su sexualidad, entre otras cuestiones.

De esta manera la institución escuela, siempre al frente de todas los hitos que marcaron la vida social de nuestro país, vuelve a reinventarse y hacerse cargo, a los manotazos, desprolijamente, pero con la responsabilidad social que se le atribuye, a ponerse al hombro la tarea de enseñanza y aprendizaje que asumió tener.

El tiempo nos mostrará los resultados de este proceso, que como sea, fué lo que mejor se pudo diseñar en un tiempo récord, en condiciones de mucha precariedad y en una contingencia que atravesó a todes les actores de la comunidad educativa. Como así también en pleno aislamiento obligatorio, tomó la tarea de abrir la escuela para brindar la asistencia alimentaria y entregar los cuadernillos a las familias del territorio. La escuela está, aún sin escuela (física). Su territorialidad 
la portan sus estudiantes, quiénes le dan sentido, quiénes a pesar de divertirse viendo el pánico de les docentes entrando a sus mundos, Elles, hijes de la era digital, responden al vínculo instituido porque necesitan la escuela, como expresaron repetidamente en sus relatos, quizá la necesiten de otras formas y será hora de que la escuela empiece a leerlas.

\section{Escenario 6. Conclusiones}

Plaza Moreno a estas horas de la mañana, se vuelve más ruidosa, los autos circulan y su sonido sacude la quietud de la noche que transcurrió al son del teclado y del ruido de palomas en las ventanas. Ya no suenan alarmas de cocheras ni de autos, solo el movimiento del tránsito que para estas alturas de la cuarentena comienza a aumentar.

Las palabras que costaron salir, luego se agolparon en el teclado. Mucho por decir, mucho por seguir investigando. Me resuenan las voces que volví a escuchar durante la madrugada, los titubeos, los silencios, los tonitos tímidos, esos "seños" tan amorosos destinados a sus maestras. Releía el escrito y me estremecía pensando en esos días en bucle, que solo se detiene durante las horas de sueño y luego, es "un todo lo mismo", como un día que se repite y se repite.

¿Cómo fugarse?, nos preguntábamos en términos simbólicos, por supuesto.

$Y$ recuperamos todos esos momentos de soledad que les niñes se atribuyen y que el mundo adulto legitima, la escuela, el juego y el ocio, jvaya que trinidad!, la misma que connota y denota el término escuela. Por algo han sido consagrados derechos de les niñes.

La escuela y el juego, son quizá los únicos espacios (salvo que haya alguna otra actividad extracurricular) que habilitan y gestionan prácticas de autonomía y autogestión. Espacios donde les niñes son niñes y ya no hijes. Si bien en la escuela se juegan prácticas de poder y subalternidad, la institucionalidad que porta la carga también de un protocolo de normativas y regímenes de actuación que si bien, establecen parámetros de control y obediencia y también dejan lugar para la transgresión sin consecuencias tan difíciles y arbitrarias como las que se rigen en la casa, donde el niñe está sole frente al poder adultocéntrico.

En la escuela les niñes pueden ser Elles. Y la opresión vivida en otros espacios, irrumpe en las aulas, en los patios, los gritos, las corridas, las travesuras, las malas palabras, los enfrentamientos con docentes. En la escuela les niñes son niñes, como en el juego, donde no son ni hijes ni estudiantes. Allí pueden elegir quien ser, que mundo conquistar, que batallas lidiar. 
En el juego tienen armas, aliades, poder, muchas veces acompañades de sus amigues compañeres de juego.

Les niñes extrañan al otro, estañan a sus pares, necesitan hablar, compartir, decir, soñar, proyectar con alguien que hable desde un lugar similar, necesitan sus amigues, necesitan a sus pares. ¿Qué sucede con los vínculos de les niñes cuando no están?, ¿Cuál es el valor de las amistades en sus vidas?, ¿Qué sucede cuando esos lazos afectivos se ven interrumpidos?, en una entrevista realizada a la neuropsicóloga Noelia Gilbert, ella decía Cuando hay una catástrofe natural grande o alguien sufre un accidente de tráfico grave es habitual que se desarrolle un trastorno de estrés postraumático (TEPT). Ocurre cuando un evento cambia radicalmente la vida de una persona, aunque sea algo transitorio y su impacto emocional sea puntual. El contexto infantil en esta crisis ha cambiado de la noche al día. No acuden a clase, no se relacionan con sus compañeros, con sus profesores, no tienen esas figuras de apego que son tan importantes para su estabilidad. Barajamos que, una vez termine la restricción, posiblemente aparezcan problemas de estrés postraumático o trastornos adaptativos. Síntomas que esperemos no se prolonguen en el tiempo"

¿Cómo hacer para qué las heridas subjetivas que va a dejar este virus, sean menos profundas?, Quizá sea la escuela una vez más, quien pueda contribuir en ello. Hacer escuela es hacer comunidad, El reloj no marca el presente, es pasado y es futuro. Hacer escuela es algo que se hace. Que no está hecho. Hacer escuela es hacer comunidad el tiempo es irrenunciable en hacer escuela, señalaba Walter Kohan en el curso de Formación Docentevi [iiii] a lo que Patricia Redondo agregaría: hay que abrir las puertas de las escuelas a la vida. La escuela está sumiendo la asistencia y el cuidado, prácticas que antes tanto ha resistido. En este momento están suspendidas las claves más arraigadas de lo escolar. Yo digo que esta pandemia será refundacional para la escuela. Por último Carlos Skliar expresa, la infancia no es un tiempo ni una edad. La infancia es cuando todavía no es demasiado tarde, es cuando todavía "hay tiempo para". Hoy se exige escuchar a la infancia. Pensar la infancia en clave emancipatoria.

¿Cómo hacer escuela entonces? Quizá, acercándose un poco más a su identidad signada por su nombre "бxoגń (skholế) - schola. "tranquilidad"- lo que se hace en el tiempo libre, de ocio," Por ahí es necesario admitir cierto espacio para la recreación, para el compartir, para reconstruir estos frágiles lazos sociales. Quizá pueda sacar del ostracismo en que cada niñe y adolescente se encuentra, yendo de la mesa al televisor, del televisor a la mesa, de la mesa a la tele o compu 
y de la mesa a la cama. Facilitando un chat por curso, consignas grupales, videollamadas, con dinámicas que permitan contar lo que están viviendo, que habiliten a que salgan en esas narrativas y otras cuestiones que quizá no estamos pudiendo leer. Si la escuela es hacer comunidad, estaría faltando ese lugar común que les encuentre.

Podemos salir fortalecides de este aislamiento, la escuela puede y debe refundarse con los sentidos que le otorgan les niñes. La escuela está. Y les niñes la necesitan. Con paredes o sin ellas.

Queremos ver corretear les niñes por la plaza de nuevo.

\section{Referencias Bibliográficas}

Butler Judith, (2020) Sin miedo: Formas de resistencia a la violencia de hoy, Taurus, Penguin Random House Grupo Editorial España.

Convención de los derechos del Niño (1989) <https://www.eumed.net/rev/cccss/19/ggm.html> Guardia, \& Kuiyan (2015) "Juego libre en las juegotecas barriales" Publicado en Memorias VII Congreso Internacional de Investigación y Práctica Profesional en Psicología XXII Jornadas de Investigación XI Encuentro de Investigadores en Psicología del MERCOSUR. Buenos Aires, 25 a 28 de noviembre de 2015.

Reguillo Rossana (2006) "En América latina hay un agotamiento institucional", Página 12, Diálogos, 4 de septiembre de 2006.

Unicef (2006) "Convención sobre los derechos del niño" $<$ https://www.un.org/es/events/childrenday/pdf/derechos.pdf> Vitaller Karina y Otros (2019) "Niñeces en escenarios de convergencia mediática" Tesis de licenciatura FPyCS, UNLP publicado en Sedici <http://sedici.unlp.edu.ar/handle/10915/88407>

\section{Notas}

i Utilizamos la palabra niñeces, entendiendo que es un modo menos violento de conceptualizar la diversidad de expresiones de la niñez, no solo reconociendo aspectos vinculadas a la diversidad sexogenérica, sino también las trayectorias de clase, territoriales, de origen, etc. Desistimos de nombrar a las niñeces como infancias como un plural posible integrador, por el sentido que este concepto encierra. El término Infans, "el que no habla", (Castello, Mársico 2005) se refiere a personas que podrían rozar hasta los 13 años, que si bien han adquirido la capacidad de hablar, sería el que no puede valerse de su palabra para dar testimonio. Este término deviene del latín y está formado por un prefijo privativo In y fari, "hablar", de allí su sentido de "que no habla", "incapaz de hablar". (Por ejemplo frente a un tribunal), sus derivados y pares griegos por ejemplo, tenían sentidos similares y hasta asociados a la condición de esclavo, de 
esta manera entendemos que el lenguaje es un terreno de luchas de sentidos, en las cuales nos insertamos y asumimos que lugar queremos ocupar.

ii Reguillo Rossana (2006) “En América latina hay un agotamiento institucional”, Pagina 12, Diálogos, 4 de septiembre de 2006

iii Butler Judith, (2020) Sin miedo: Formas de resistencia a la violencia de hoy, Taurus, Penguin Random House Grupo Editorial España

iv La palabra "catástrofe" deriva del griego катабтрофń (katastrophe - ruina, destrucción) у está formada de las raíces катò (kata = hacia abajo, contra, sobre) у бтрофń (strophe = voltear), o sea "voltear hacia abajo", suceso fatídico que altera el orden regular de las cosas.

$\checkmark$ Trauma deriva del griego y significa "herida" en este sentido está usado desde su acepción de trauma emocional, de "herida psicológica" un trauma es un hito que afecta nuestra calidad de vida, generando desordenes psíquicos, el cuál puede ser provocada por situaciones generalmente extraordinarias, inquietantes, abrumadoras y que no son de carácter usual. No tienen que ver tanto con la dimensión del evento, este puede ser un accidente, una mudanza, lo que determina el daño va a ser la contención afectiva, el momento de su vida y su reiteración o duración del evento que lo produjo.

vi Curso de Formaciòn Docente: Conversaciones en la sala de Maestrxs y Profesorxs para el espacio No dejamos de enseñar. Aportes pedagógicos para cuidarnos entre todxs, desde AMSAFE invitamos a participar del ciclo Conversaciones en la sala de Maestrxs y Profesorxs. 7/5/2020 con la participación de Walter Kohan, Patricia Redondo y Carlos Skliar con la propuesta Tiempo de hacer escuela, de hacerse infancia. 